Roth, W.-M., \& Friesen, N. (in press). History and the relationship between scientific and pedagogical knowledge: anatomy lectures then and now. Journal of Curriculum Studies. doi: 10.1080/00220272.2013. 773597

\title{
History and the relationship between scientific and pedagogical knowledge: anatomy lectures then and now
}

Wolff-Michael Roth, University of Victoria

Norm Friesen, Thomson Rivers University

\begin{abstract}
In recent years, school science has been the target of increasing critique for two reasons. On the one hand, it is said to enforce "epic" images of science that celebrate the heroes and heroic deeds that established the scientific canon and its methods and thereby falsifies the history and nature of science. On the other hand, the sciences are presented as objective, making factual statements independent of location and time - a claim which runs counter to the current mainstream canon of scientific knowledge as socially and individually constructed. In this article, we suggest that contexts leading to new scientific knowledge make science objective and subjective simultaneously. Our approach, which focuses on the performative dimensions of (school) science, works to overcome the distinctions between knowledge and knowing and the associated distinction between theory and practice. We show the significance of the performative dimension through a comparison of anatomy lectures and texts from the 17th century and in present-day biology classrooms. We underscore the need to retain and investigate the historical connections between the founding of (scientific) knowledge and its present-day form taught in schools.
\end{abstract}

Keywords objectivity; subjectivity; performativity; science history 
$[\mathrm{R}]$ econstructing the relationship between scientific and pedagogical knowledge- - which need always be a historically contextualizing exercise-is not only an urgent necessity in the history of every discipline and in research into the modes of cultural communication. It also contributes to further establishing academic education. (Tröhler 2008: 84)

All knowledge has a cultural history, including pedagogical knowledge and knowledge of the content that subject matter specific pedagogy is intended to teach. This history tends to be rewritten following scientific revolutions (Kuhn 1970), which then leads to the fact that in the curriculum the 'sensual imagination of concepts by means of the figures of the [present-day] drawing surreptitiously replaces the real constitution of ur-idealities' (Husserl 1939: 217). ${ }^{1}$ That is, by encountering science as it is today, students no longer are afforded the possibility of reliving the transition from the original common sense ('ur-ideality') to scientific sense. Although scientific knowledge can be handed down without drawing on ur-idealities, what is lost in the process is the 'capacity of the reactivation of the ur-beginnings, that is, the sense sources for everything that follows' (Husserl 1939: 217). That is, precisely those experiences get lost that have been, and continue to be, foundational to the 'intuitive', prereflective, or pre-noetic sense of scientific concepts. It is perhaps not surprising then that the author of the introductory quotation suggests that there is a necessity to reconstruct the relationship between the two forms of knowledge because it 'contributes to further establishing academic education'.

Why we should be interested in providing curricular opportunities for re-living the urbeginnings has been established some time ago using geometry as an example. Thus, geometry specifically and all sciences generally are understood not only in their continual development but also as a continuing synthesis whereby everything acquired acts from within to preserve the original constitution of new knowledge to the present day (Husserl 1939). Because a science generally and new paradigms specifically emerge from something that had a more primitive and

\footnotetext{
${ }^{1}$ An import from the German language, the prefix $u r$ - stands for 'original', 'earliest', or 'primitive'.
} 
less developed sense, the very fact of the emergence of a science or scientific paradigm constitutes an experience that invisibly works within that science to the present day. This is important in a context where science educators have called, for example, for the 'eradication' of 'misconceptions' such as the Aristotelian idea about force as inherent in a moving object (Barke et al. 2009). However, the Galilean viewpoint — now recognized as the scientific canon — arose from a worldview and Zeitgeist reigned by an Aristotelian discourse on motion. But this discourse was not fixed. As the history of science shows, this discourse in fact constituted the ground, resource, and the means for overcoming itself. This is not any different today, where children's commonsense, often unscientific or pre-scientific discourses provide the very resource for making statements about scientific objects. Even if a child has never thought about the motions of sun and earth before, from the everyday language (e.g., 'the sun rises [in the east]', 'the sun sets [in the west]') new statements can be made that science educators declare to be unscientific (e.g., 'the sun moves around the earth'). But this language, as unscientific as it might sound, is the basis for some children to become scientists (Roth 2008). Everyday common sense and lifeworld experience, as unscientific as they may be, are the very foundation of any system of abstraction or science (Husserl 2008).

The purpose of the present paper is to engage in and exemplify such a reconstruction of the relation between scientific and pedagogical knowledge with concrete materials from lectures and texts that (a) inaugurated a modern understanding of the heart and circulatory system and were part of the emergence of present day scientific method and (b) exist as anatomy lectures recorded in an 12th-grade biology classroom. Such a move, which 'places educational works which mediate between academic knowledge, historical context and pedagogical technology, at the focus of educational reflection' can only reap profits (Tröhler 2008: 84). In this reconstruction, we heavily draw on the work of E. Husserl, who not only was a philosopher but also a mathematician (his $\mathrm{PhD}$ was in mathematics). The question may be raised whether a study of the origin and history of geometry also pertains to science. The question has been answered in the affirmative, because geometry serves Husserl as an example for the crisis in the European 
sciences in a more encompassing philosophy of history (of science) (Derrida 1962); and in this overall project, the text on the origin of geometry 'would not but explicate the dialectic of "protention" and "retention" described in the lectures on the "internal consciousness of time"" (Derrida 1990: 22, our translation).

\section{Reactivating the originary constitution of a sense configuration}

The sciences change and, therefore, have a history. Although the sciences are handed down by means of practices and artifacts, what tends to be hidden and invisible today are the foundations that make them the objective sciences that they are (Husserl 1939). How did the sciences emerge from something that was not 'scientific' at all? This question reappears each time a scientific revolution occurs: How do new paradigms emerge from the contradictions of old patterns of understanding? This question also is pertinent to learning science in the presentday classroom: How do students, who bring non-scientific, everyday language (ideologies) to the science classroom, acquire - if they do at all — the 'revolutionary' new language? For Husserl, these questions lead us back to the original constitution of the (new) science. To understand the constitution of a new form of knowledge, we need to understand that which preceded it. This is the ground, material, and tool on the basis of which the new emerges. These older forms of knowing are not to be disregarded as something lesser but rather constitute the very conditions for the new to emerge. The important insight of Husserl lies in the fact that the original sensegiving (sinnstiftende, sinnbildende) act is reproduced each and every time the relevant aspect of science is performed (e.g., Bjelic 1992, Bjelic and Lynch 1992). Crucial to the reactivation (Reaktivierung) of the original sense-giving act are those segments of the material continuumincluding sound-words (Sprachlaute) and written signs - that are associated with the constitution of the science. Together, the sense-giving act, and the practical accounts of it in word and writing (science as an finished object that appears in textbooks) make up a 'Lebenswelt pair' (Bjelic 1996, Garfinkel 1996, Livingston 1986). Here, Lebenswelt is the world as encountered in 
everyday life, at home as much as at work. The Lebenswelt pair refers to the observation that any social or natural fact is constituted by real embodied work, on the one hand, and (verbal) accounts or finished products, on the other hand.

The finished object is crucial for the nature of science. Thus, 'the important function of writing is to make possible the continued objectivity of the ideal sense configuration [Sinngebilde] in the curious form of virtuality' (Husserl 1939: 212, original emphasis). To become real, the virtual sense configuration has to be concretely enacted to actually exist. When it is documented in material form, that is, in the form of an artifact, then the ideal object (Gegenstand) can be reproduced concretely at any time in subsequent history. But discourse and the artifacts change, thereby black-boxing the origin of the science. This leads to the fact that 'the original concrete perception and thought and observation-related statements, which produces the originally evident gestalt in activities based on sensual experience' (Husserl 1939: 213) becomes invisible. However, it may become visible again in every act that reactivates and, therefore, reconstitutes the sense configuration.

In the 'science wars', two contradictory framings of the nature of science came to be confronted: science as objective and science as constructed subject to social and material contingencies (e.g., Gross and Levitt 1994, Labinger and Collins 2001). In (science, mathematics) education, a move could be observed toward the constructivist end of the debate. However, science is not just constructed, made up in a fashion where, as it were, 'anything goes'. Rather, there exists a dialectic relation between science as objective and science as subjective. Science is objective (and therefore useful) in that it can be reproduced in the same way across historical time and, simultaneously across geographical space. Science is subjective in the sense that it takes inherently embodied and situated, always practical action to constitute sense. This is apparent from the following example from the history of anatomy and its emergence as a science in the modern sense. In On the Motion of the Heart and Blood in Animals, Harvey (1889) makes an argument to his colleagues that the blood is pumped around in the circulatory system. He suggests that the valves serve to prevent blood, which he says moves from larger towards smaller 
veins from flowing backwards 'whilst the motion that proceeds from the lesser to end in the larger branches is favoured, or, at all events, a free end open passage is left for it' (Harvey 1889: 68). Up to this point, his statements may be read as claims. Harvey, therefore, proposes a little experiment that enables 'that the truth may be made the more apparent' (Harvey 1889: 68). He provides a verbal description and drawings that together may serve as instructions for anyone to reproduce the observations on which his claims are built (figure 1). When the actions described are performed (tying up the arm as for phlebotomy, for example, to collect a blood sample), then observations can be made. If a finger is held as in the second drawing (figure 1), then the observer 'will see no influx of blood from above' (Harvey 1889: 68). Thus, this text together with images provided, when read as an instruction for doing and observing, constitute a sort of recipe for reactivating precisely that which has led to origin of modern anatomy and the scientific revolution concerning the circulation of the blood and the function of the heart. That is, whoever conducts this experiment today has reactivated the original, sense-constitutive praxis.

\section{«"«"«" Insert figure 1 about here "॥"»"»»}

The text and the images serve precisely to institute the conditions underlying any possibility of a reconstitution. Thus, pertaining to the reproduction of geometry, 'it is evident that first the method of the production of the original idealities from the pre-scientific givens of the surrounding lifeworld (Lebensumwelt) have to be written down and fixed in constative statements prior to the being of geometry' (Husserl 1939: 216). In his books and lectures, William Harvey has done precisely that. His observations are stated over and against what came to be the pre-scientific once the scientific revolution was recognized as such (e.g., see the examples below). Those competencies required for translating Harvey's statements into the reactivation of the evident sense have to be acquired, which tends to be done in and through quasi-formal demonstration and instructional engagement. Such reactivation may occur in school instruction (Unterricht) where students come to be confronted, in lectures and books, with those materials signs that are integrally related to sense constitution. However, it does not occur when students only come to act on and interact with the finalized concepts and statements ('fertigen 
Begriffen und Sätzen', Husserl 1939: 217). This is especially the case, for example, when students simply verify something like Galileo's law of motion rather than engaging in an effort of practically understanding those conditions when Galileo's law is not observable, that is, when the phenomenon is actually lost (Garfinkel 2002). We show below how in a present-day lecture, the material artifacts and the embodied performances of the lecturer may make it possible for the audience to make observations of the kind that led to the original constitution of sense. That is, the students vicariously and mediated by signs reproduce observations that would have been made if they had actually vivisected an animal.

Any original constitution is passive because from the perspective of the old knowledge (prescientific or original paradigm) the new cannot be anticipated (Husserl 1939). But together with the original constitution of sense there is another constitution (Mitstiftung): 'the possibility of arbitrary repetitions based on the identity of the configuration in the chain of repetition' (Husserl 1939: 211). That is, with Harvey's original statements the possibility is created for the unlimited repetition of his observation: directly or vicariously.

Important in this historical reconstitution of sense is the role of representations, that is, entities that make phenomena present again (re-) when these are in fact absent (Husserl 1928). In the course of scientific history, these representations change. Thus, for example, the original formulation and proof of the four equations of electrodynamics relating electric and magnetic fields and sources took 54 pages of a scientific journal (Maxwell 1865); the entire accomplishment today is represented in four brief equations that appear in such media as physics textbooks and Wikipedia entries. They are basic elements in the training of physicists (including the first author). To recover the relationship between the original formulation and the appearance of Maxwell's equations today requires considerable practical competencies in mathematical physics. But precisely because they are compact, these equations are easily recalled, ready to hand, and afford the rapid solution of complex problems in electrodynamics.

\section{Motions of the heart and blood: from dissection and vivisection to anatomy lectures}


In this section, we present materials from William Harvey's lectures and his book On the Motion of the Heart and Blood in Animals, which subsequently were reified as having brought about a scientific revolution (or a paradigm shift) in medicine. We contrast these with materials from a modern-day series of seven lectures on the heart and circulatory systems in a 12th grade biology course. Although we original Latin Exercitatio anatomica de motu cordis et sanguinis in animalibus (Harvey 1628) as facsimile, and although we can verify that available translations not only differ from each other but also from the original, our school Latin is insufficient produce good translations ourselves. In this paper, we therefore draw on the one Robert Willis originally produced in 1828 , one of two translations that some scientists have more recently recommended (Glimcher 2005).

William Harvey is recognized to be one of the founders of anatomy, as the 'father of modern physiology' (Medical Discoveries 2012), and as one of the founders of science in the modern sense. He is best known and celebrated for his contributions to the understanding of the circulatory system in the way it is understood today. The results of his work continue to be taught as an exemplifying case of the epic character of the sciences (van Eijck and Roth 2011): His portrait figures prominently in the sidebars of introductory biology textbooks and his illustrated instructions of how to verify the flow of blood are valid today as they were during Harvey's time. The vivid descriptions of the movements of the heart available in Harvey's lecture notes generally and in what was then a revolutionary text On the Motion of the Heart and Blood in Animals more specifically provide us with a basis for understanding the origins of this dimension of scientific knowledge. An integral aspect of Harvey's texts is that they contain references to the canon of the day, the commonsense ground in and on the basis of which the revolution occurred. This knowledge, of facts and of method, constituted the very basis, material, and tool with which the revolution was brought about.

In his lectures and book, Harvey is pointing out something unknown and controversial at the time. He was the first to assert that the heart functioned like a pump for the purpose of 
circulating blood throughout the body. However, he does more than that. He provides instructions to fellow physicians and anatomists to on what to do to make specific observations. These observations, then, can be said to exist independent of the particular anatomist. They reveal the 'fabric of nature' itself - as long as the fellow physicians were to perform the actions in the manner that Harvey describes. It was only later that Harvey came to be recognized as having constructed a conception of the function of the heart (circulation of blood), associated with this function a new system or bodily function (circulatory system), and delimited this system from others in the body (e.g., from the respiratory system).

In his anatomical studies of the motion of the heart and blood, Harvey always begins by acknowledging the authorities associated with the knowledge available at the time: Aristotle, Galen, or Andreas Laurentius. He then moves on to describe something that contradicts the available knowledge and that generally is not shown during his lectures: a live dissection or vivisection of an animal. (There was only one sanctioned public human dissection per year, which was attended by fellow physicians.) Although in his textual work these are represented in verbal form, Harvey appeals to his public dissections where members of the Royal College of Physicians had been present and observed what his texts describe:

Were not the work indeed presented through you, my learned friends, I should scarce hope that it could come out scatheless and complete; for you have in general been the faithful witnesses of almost all the instances from which I have either collected the truth or confuted error. You have seen my dissections, and at my demonstrations of all that I maintain to be objects of sense, you have been accustomed to stand by and bear me out with your testimony. (Harvey 1889: 5 [1628: 6])

Overturning the existing canon is possible because, as Harvey admits, he does not reproduce the knowledge of the anatomists of the past, which he would recite and thereby 'make a parade of the strength of [his] memory' (Harvey 1889: 7 [1628: 8]). Rather, he 'profess[es] to learn and to teach anatomy, not from books but from dissections; not from the positions of philosophers but from the fabric of nature' (Harvey 1889: 7 [1628: 8]). Harvey's books employ the verbal 
mode. In On the Motion, there is only one page with four naturalistic drawings featuring two arms with a rubber band about the upper parts, on one the fingers of another hand compress an artery leading to an apparently empty blood vessel (figure 1). But even these illustrations are not necessary, precisely because he encourages his fellow physicians to remember the public dissections that they had witnessed and because his descriptions are sufficient to reproduce the observations if a learned reader were to conduct vivisection himself. Not surprisingly, perhaps, Harvey's descriptions turn out to be particularly vivid yet, in part constituting what is to become the scientific genre, dispassionate: 'when the chest of a living animal is laid open and the capsule that immediately surrounds the heart is slit up or removed, the organ is seen now to move, now to be at rest' (Harvey 1889: 22 [1628: 21]). As a result, one can make observations: 'there is a time when it moves, and a time when it is motionless' (Harvey 1889: 22 [1628: 21]).

Harvey describes observations that he has made while opening the chest of living animals. He points out the conditions when the motions are more and when they are less obvious, thereby assisting any anatomist trying to reproduce his findings to seek out instances that would more clearly exhibit relevant features. For example, he writes that the things he noted in the quoted paragraph 'are more obvious in the colder animals, such as toads, frogs, serpents, small fishes, crabs, shrimps, snails and shell-fish' (Harvey 1889: 22 [1628: 22]). He then continues to suggest that these movements can also be observed in warm-blooded animals, especially 'when the heart begins to flag, to move more slowly, and, as it were, to die' (Harvey 1889: 22 [1628: 22]). In such a case, 'the movements then become slower and rarer, the pauses longer, by which it is made much more easy to perceive and unravel what the motions really are, and how they are performed' (Harvey 1889: 22 [1628: 22]).

Important to the learning from 'the fabric of nature' are observations. These observations are described in a particularly vivid language. For example, Harvey notes how the heart is laid bare by cutting open and removing the capsule surrounding and protecting it. His descriptions are sufficient to serve as instructions, allowing anatomists to reproduce the operations much like a cookbook recipe instructs the (hobby) cook to engage in an action until some observation is 
made. Thus, a bread recipe might state 'Knead the dough for 10 minutes, until smooth, springy and satiny'. In such situations, an action is to be continued until a particular observation can be made. In fact, if the observation is not made, the person-everyday folk, expert, and scientist alike - perusing the recipe or plan may conclude that the action itself is problematic (Roth 2009).

After completing the clearing of the heart, the following observations should be made, serving as a checkpoint for assessing the preceding performance: 'the heart is erected, and rises upwards to a point [or apex], so that at this time it strikes against the breast and the pulse is felt externally' and that 'it is everywhere contracted, but more especially towards the sides so that it looks narrower, relatively longer, more drawn together' (Harvey 1889: 22 [1628: 22]). He describes that the color of the heart is paler during contraction than when it is 'quiescent', at which time it is a 'deeper blood—red' (Harvey 1889: 23 [1628: 22]). But Harvey appeals to other senses as well. For example, he notes what can be felt, taking us back to the very embodied experience that the anatomist has with the phenomenon: 'The heart being grasped in the hand, is felt to become harder during its action. Now this hardness proceeds from tension, precisely as when the forearm is grasped, its tendons are perceived to become tense and resilient when the fingers are moved' (Harvey 1889: 22 [1628: 22]).

Although recognized today as a founding father of anatomy and physiology, and although he had provided evidence for his theory in public dissections, Harvey 'provoked immediate controversy and hostility from the medical community of the time' because he was contradicting 'the usually unquestioned teachings' (Medical Discoveries 2012) of the ancient Greek physician Claudius Galenus generally known as Galen (AD c. 130 to c. 200). After the publication of his disputation on blood, Harvey 'fell mightily in his practice' and that he was seen to be 'crackbrained' 'by all the physitians [sic] who were against him' (Nature 128: 507).

\section{Motions of the heart and blood in 21 st century anatomy lectures}

In this section, we present materials from a 21 st century biology class, where the motions of 
heart and blood where presented in the course of seven lectures. Central to the presentation are not only the chain of representations of the heart and circulatory system but also the performative dimensions that provided opportunities for students to see movements of the kind that Harvey would have observed. In this way, the lectures provide perceptual experiences that are foundational to the constitution of the originary sense that underlies present-day understandings of human physiology and anatomy. In this paper, we draw on the videotaped lessons and transcriptions made thereof; and we understand the lecture as a performance in which scientific concepts (contents) were staged and come to life for the audience (PozzerArdenghi and Roth 2007, in press). In our analyses, we hold it with Gaston Bachelard (1949/1966), who understands the real as a concrete case of the possible. Thus, these materials from the specific lectures we recorded constitute concrete realizations of cultural possibilities and, therefore, provide us with access to a general rather than singular way of presenting biological concepts. Because of our interest in the performative dimensions of the lectures, we do not draw on students' notes in the presentation that follows.

\section{Representing the heart in 21 st century lectures}

In the course of the lectures, increasingly abstract means were used to make the heart present in the lecture. The adjective 'abstract' here denotes the fact that there is less and less family resemblance between the means of making the heart or circulatory system present in the classroom and the original phenomenon. Thus, the teacher initially had used a 3-dimensional model of the heart. As he talked about the parts of this model heart, he produced a naturalistic drawing on the chalkboard (figure 2, left). Throughout the lectures, he also made reference to his body where his (invisible) heart pumps the blood through the circulatory system. Other forms of making the heart present included professionally rendered naturalistic drawingsdrawn (figure 2, left), available in charts, or on overhead projected drawings — and abstract diagrams that consisted of no more than a square subdivided into four smaller squares (figure 2, 
top and bottom right). That is, this series of lectures produced signs standing in for the (absent) heart and its functions that had less and less perceptual similarity with a human heart: The teacher engaged in the production of a chain of signification constituted by different forms of inscriptions (3-d model, on the chalkboard, overhead projector). Although it might be assumed to be self-evident that the three inscriptions in figure 2 all pertain to and stand in for the heart, it has been suggested that any two inscriptions are fundamentally different and separated by an ontological gap (Latour 1993). The adjective 'ontological' points to the fact that there is a difference in kind: There is no natural connection across this gap. Thus, even experienced and successful scientists make inappropriate connections between inscriptions and natural phenomena, and they do so even in introductory lectures (Roth and Bowen 1999). This gap tends to be bridged only in and by the embodied social practices and situated actions of those familiar and competent with their mobilization (Roth and McGinn 1998). As we show below, it turns out that the teacher provided resources for noting and experiencing continuity across the different representations and, therefore, across the ontological gaps.

\section{«"แ"แ" Insert figure 2 about here "'"!"!")}

The heart, however, is not something static in its appearance but dynamic. This dynamic dimension comes into play by means of the gestures that the teacher performed over and above his body, creating the ephemeral impression of the flow of the blood. In other words, once a naturalistic drawing or diagram appeared on the chalkboard, it became an occasion for further elaboration of the function of the heart. In the lectures, this heart re/appeared in four presentational forms: in the body of the lecturer, who makes a gesture with respect to his own body of the blood flow through the heart, as the physical model, as a diagram, and in discourse. Indeed, there was a co-location and alignment of all four presentational forms. While holding the model heart in front of the diagram, its apex aligned with that of the diagram, the teacher makes a hand gesture past his own heart and towards his head with the thumb indicating the direction of blood flow generated by the 'left ventricle', which is 'a massing pumping chamber that sends blood all the way up to the head'. Continuously holding the model in the left hand at the same 
location in front of the apex of the diagram, the teacher gestured the blood flow with respect to his own body 'all the way down to the capillary circuits at the tips of your toes'. There is actually a complex performance where the specific body of the teacher becomes an instance of all possible human bodies, which left it up to the audience the work of distinguishing whether he referred to the body in general or to his body (Pozzer-Ardenghi and Roth 2009). But the biology teacher did much more to bring the static inscriptions to life, as we show in the next subsection.

\section{Performing the heart in narrative space}

Recurring gestures constitute one of the ways in which performances over and against multiple presentations and presentational forms come to linked. For example, with respect to the function of the heart, there are two main processes involved: the heart is pumping the blood out through the left ventricle and into the circulatory system and receives it through the right ventricle, where the deoxygenated blood from the right atrium arrives. The out movement comes to be associated with a characteristic hand gesture that repeats itself over and above different presentations. Similarly, talk about the receiving function is associated with a characteristic gesture that repeats itself across presentations in the course of the seven lectures.

During the lectures, these inscriptions were brought to life not only because they were integral and constitutive moments of the presentation as a whole but also because they came to function as the (theatrical) backdrop against which bodily performances generally and gestural performances specifically played themselves out. One way in which the teacher referred to the heart was by pointing to his own body. He did so in a bodily orientation and spatial location that has been referred to as 'narrative space' where presentations appeal to experiences in the real world (Roth and Lawless 2002). In contrast to 'inscription space', where the lecturer is oriented towards the medium where the 2-dimensional visual representation appears (gestures move in a plane), this narrative space is characterized by a body turned (almost) entirely toward the audience and by iconic gestures that operate in all three spatial dimensions. In the absence of the 
living heart or other innards that the audiences of public surgery and vivisection might have seen, the biology teacher's performances played out essential aspects of the living aspects not only of the heart but other parts of the human body and phenomena (birth, visit to the doctor who does a reaction test).

In his text, Harvey notes that the heart can be seen to become erect, hard, and to be of diminished size when studied in its movement. These are precisely the observational particulars indicated through the teacher's gestures that were recorded as he enacted a contraction of the heart in narrative space. The movement of the teacher's body began in a lowered position with the elbows far out sideward and high, the hands held as if these were touching the outside of a big drum (figure 3a). As the hands moved inward, the elbows moved downward and inward whereas the upper body moved upward (figure $3 \mathrm{~b}$ ) coming to an erect position when the hands had reached their nearest distance and the elbows have come to rest against the torso (figure $3 \mathrm{c}$ ). Precisely coordinated with the movement is the articulation of the associated performance of the heart: it is conTRACting. In the first phase of the moment (figure 3a-b, we hear an unstressed 'con-', whereas in the second phase we hear the stressed 'TRACt' with the movement of the arms and hand to the torso (figure 3b-c); the 'ing' ending is articulated in the final resting phase of the gesture (beginning with figure $3 \mathrm{c}$ and following). The video also reveals the apparent effort involved in the preparation and action phase of the pump: in the facial expression. This facial expression returned to a relaxed state in the final phase, coinciding with the unstressed ending of the performative verb (i.e., '-ing'). We can literally observe, across the modalities of hearing and seeing, the constricting movement that occurs simultaneous with the erection.

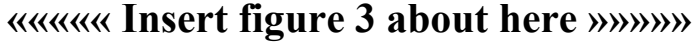

Similarly, Harvey noted that the heart, 'when it relaxes and sinks together it receives the blood in the manner and wise which will by-and-by be explained' (Harvey 1889: 24-25 [1628: 24]). In the biology lectures, we find a recurring gestural feature associated with the reception of blood by the heart during its relaxation stage that followed the contraction. In figure 4 we observe one of these occurrences, in the form of a two-handed gesture. The gesture begins with 
the arms stretched out toward the class, hands turn upward with open palms, as if these to receive something. The arms then move backward until the hands nearly touch the teacher's torso. The sound-word 'receiving' begins precisely when the hands are in the most forward position and ends when the hand have arrived in their final position. The speaker then continued with the word. The stroke (central) part of the gesture falls together with the central part of the word: reCEIVing.

\section{«"«"«" Insert figure 4 about here "'"»"»"»}

'Up and out': repetition and difference in the performance of the 'forcible expulsion of the blood'

The observations in the preceding subsection were not singular. A pervasive feature of the series of lectures was the recurrent use of gestures that were recognizably the same in different contexts. Thus, across the lectures on the circulatory system, the biology teacher uses a variety of gestures that repeat across lessons and in the context of many different inscriptions that he makes use of, both those that he drew on the chalkboard and those that had been prepared previously for the occasion (overhead) or that have been purchased (maps, model). The repetition of the movement sequence itself had the quality of a (slowly) beating heart, exhibiting both movement and therefore difference - the lecture had covered more and different groundand repetition. There were some aspects that remained the same as the unfolding lecture developed and changed: certain gestures repeated over and against different representations, constituting new performances with an underlying theme marked as constant by the repetition of specific gestural performances. In this section, we take a look at those gestures and representations related to the flow of blood from the left ventricle and out.

In his work on the heart, blood, and the circulatory system, Harvey emphasized the forces that are perceptibly at work when the open heart is observed and touched.

These things, therefore, happen together or at the same instant: the tension of the heart, 
the pulse of its apex, which is felt externally by its striking against the chest, the thickening of its parietes, and the forcible expulsion of the blood it contains by the constriction of its ventricles. (Harvey 1889: 23 [1628: 23])

In the preceding section, we already note how the biology teacher performed the contraction and constriction of the ventricle, which forces the blood up and out of the left ventricle and into the circulatory system (up into the head and down to the most distant capillaries). As the course progresses over the course of the 7 lectures, the 3 -dimensional model of the heart no longer appears; and the lecturer relies very little on naturalistic drawings (e.g., figure 2, left). Rather, the heart is rendered or made present by means of very simple diagrams (two of which are seen in figure 2, right). These simple diagrams consist of little more than a square box divided by two lines into four areas (the four chambers), with the left and right ventricle identified by means of the letter pairs 'LV' and 'RV'. (In the final version of this diagram, even the LV and RV no longer are marked, e.g., figure 2, bottom right.) As teacher said 'The heart takes it from the left ventricle up and out', his right hand with index finger stretched out performs a movement that begins at the 'chamber' marked 'LV' and moves, along the center line of the diagram, 'up and out' (figure 5).

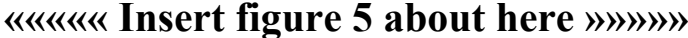

The teacher not only named features but also made certain aspects salient by prosodic means. Thus, in his prosody there was a feature that is consistently recurrent across the lecture, whereby the 'UP' and 'OUT' of the blood flow stood out against the remainder of the talk (figure 6). In the phrase 'takes it from the left ventricle up and out', the pitch rose suddenly with the pronunciation of 'up' (from $150 \mathrm{~Hz}$ to $244 \mathrm{~Hz}$ ) and, in the pronunciation of out, there was a rise in pitch from $125 \mathrm{~Hz}$ at the end of 'and' to $159 \mathrm{~Hz}$ at the beginning of 'out'. There was also a 6 $\mathrm{dB}$ increase in speech intensity, which corresponds to a four-fold speech volume. The speech energy of the voice $\left(1.87 \mathrm{mPa}^{2}\right)$ increased by $20 \%$ with respect to the mean of the surrounding speech $\left(1.57 \mathrm{mPa}^{2}\right)$. That is, the prosodic enactment of the words 'up' and 'out', were iconically related to the force of the heart pushing the blood from the left ventricle into the right ventricle and 
then out into the circulatory system.

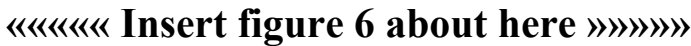

Although the gestures could be recognized as 'the same' these were actually never exactly the same. There was repetition and difference simultaneously. For example, in some repetitions, the gesture was two-handed, in other cases one-handed, the orientation-because of inscriptioncentered talk - toward the diagram (figure 7). In both instances, we observe the teacher oriented towards the inscription (i.e., in deictic, inscriptive space near the blackboard). The inscription, therefore, might be seen as function like a base beat in music. But just like the beat changes in music to mark a rhythm as rhythm (Brüstle et al. 2005), the inscriptions that make the phenomena present again changed in the course of the lectures. The particular gesture then operates like a recognizable melody in a different key or other form of recognizable modification of the original. Even though the two gestures are different, they can be recognized as the same, thereby contributing to the coherence of the topic across performances.

\section{««"«"« Insert figure 7 about here "'»"»"»"}

\section{The value of bodily and gestural performances}

In the preceding section, we provide evidence from the modern-day biology lectures that the performative dimensions of the lecture allowed students to make observations-e.g., of constriction, erection, and blood flow - that Harvey would have made during his vivisections and dissections. The lecture thereby appealed to a fundamental sense that also was constitutive in the establishment of modern-day anatomy and physiology. The lecture appealed to the sense even though the particular gestures and hand movements were unlikely those that Harvey had used. Rather, the lecture, as performance, required perceptual forms that also would have been required of Harvey's readers who had to reproduce what they had seen in the lectures or what they would have seen in their own vivisections. In so doing, the lecture can only appeal because what any student actually perceives cannot be predicted given the passive dimensions of a first 
constitution. This is so because in any first constitution of new (scientific) knowledge, be this an aspect of cultural history or individual development, a revolutionary movement occurs from the pre- or non-scientific to the scientific. What the constructivist literature that calls for the eradication of 'misconceptions', 'prior frameworks', or 'conceptual change' does not sufficiently theorize are two important aspects. First, the (radically) new emerges on the ground of, with materials from, and using the tools of its predecessor. Second, the (radically) new cannot be seen in advance of its manifestation and, therefore, remains the unforeseen until its appearance (Roth 2012). Thus, any original constitution has an essentially passive aspect (Husserl 1973). Even the most mundane things (a chair, hammer, or table) initially are given to us rather than actively constructed.

When students learn something new in lectures, they are in a situation of a first constitution. Because they are not yet familiar with sense configuration, the relation between different inscriptions denoting the heart has to be established in a coherence that arises from praxis. One aspect of the lectures presented above constitutes in allowing students to see whatever is central to be seen in the re/constitution of this form of cultural knowledge. What is to be seen, however, is not self-evident and the students in the same class observing demonstrations actually make very (significantly) different factual observations; this leads to failures to learn from lectures and demonstrations (Roth et al. 1997). In a dialectic of repetition and difference (Deleuze 1968), however, sameness can in fact appear in the face of evident differences. Sameness cannot exist unless there is difference. This dialectic allows for coherence, where there is, for example, one underlying idea that nevertheless manifests itself in different ways. The lectures that vary inscriptions, gestures, prosody, and verbal statements but also leave and mark them as pertaining to the same (e.g., 'the movement of the heart and blood'). In this way, the performance of these lectures allows the entirety of the sense configuration (Sinngebilde) to emerge today as it has emerged around the turn to the 17 th century.

Harvey already noted that it is difficult to understand the movement of the heart from direct observation ('I was not surprised that Andreas Laurentius should have written that the motion of 
the heart was as perplexing as the flux and reflux of Euripus had appeared to Aristotle', Harvey 1889: 20 [1628: 20]):

For I could neither rightly perceive at first when the systole and when the diastole took place, nor when and where dilatation and contraction occurred, by reason of the rapidity of the motion, which in many animals is accomplished in the twinkling of an eye, coming and going like a flash of lightning; so that the systole presented itself to me now from this point, now from that; the diastole the same; and then everything was reversed, the motions occurring, as it seemed, variously and confusedly together. (Harvey 1889: 20 [1628: 20])

A first benefit of gestural performance of the motion of the heart derives from the fact that these gestures foreground precisely those aspects that would be difficult to pick apart in direct observation. Most or all of Harvey's predecessors misread the motions, which Harvey understood in exactly the 'very opposite of the opinions commonly received' (Harvey 1889: 23 [1628: 23]). These performances took on different speeds and could be repeated whenever required. When the same gestures occurred against different inscriptions, the total performance in context therefore contains a repetitive (though never precisely the same) moment, which has come to be called a 'catchments' in gesture studies (McNeil 2005). A catchment constitutes a recurrent gesture feature across different speech contexts. Thus, 'the catchments created by a given speaker, we can see what this speaker is combining into larger discourse units-what meanings are being regarded as similar or related and grouped together' (McNeil 2005: 117).

Second, when gestures recur over and against different inscriptions, they mark that there is identity in the face of difference. Like music, where the melody continuously changes while the beat may remain constant, thereby 'holding together' the piece into unitary whole, the repeating gestures 'hold together' the different inscriptions into one theme. But the reverse is also the case in that the same inscription may serve as the beat that holds together different instantiations of the discursively and gesturally produced sense (i.e., 'melody').

Harvey's observations constituted the foundations and bases, which now are recognized to be 
'pre-scientific', from which his work emerged. One of the central issues of the historicity and objectivity of any science is the interplay between the formal representations (inscriptions) that can be found in books (today on the internet, in video-recordings) and the acts that actually constitute the reproduction of the knowledge in and through the singular praxis of the individual (scientist). An important aspect of the founding gesture is the "possibility of arbitrary repetitions with evidence of the identity of the [sense] formation in the chain of repetitions' (Husserl 1939: 211). The gestural and bodily productions on the part of the teacher, who 'operated' in the lecture theater, provided opportunities for his students to make observations of the kind that Harvey observed but which may require amplification and isolation to be recognized for the relevance they have to the model to be taught. The observations, in a particular form, came to life again in the teacher's performances. Without the performative dimensions of the lectures, the students might not see what is required to understand the present-day knowledge about the heart if they were to observe a video (e.g., on YouTube). This allows the reproduction of science on the parts of others, who understandingly follow [nachverstehen] the presenter in his understanding. 'As in rememorating, this complete subsequent understanding [Nachverstehen] of what is evident is taking place necessarily in their own co-execution [eigener Mitvollzug] of the producing activity' (Husserl 1939: 212). In the case of the biology lectures, the students were provided with the opportunity to reproduce a form of observation, which, because these are their own, difference and repetition contribute to their production of understanding of what others have come to understand prior to them.

\section{Coda}

In this paper, we illustrate how, from Harvey's the 17th century investigations to a lecture in the present-day classroom, from the 17 th to the 21 st centuries, the production and reproduction of scientific knowledge occurs through the performance and reactivation of a range of sensual and sense-giving (sinnstiftende) acts. In the case of Harvey's work, these take the form of empirical, corporeal recollections and observations, and their re-enactment through vivid but 
dispassionate textual description. In the case of the contemporary lecturer in anatomy, this performance and reactivation occurs through an elaborate chain of representations (inscriptions), gestures, and enactments. These representations and enactments not only include prepared, professionally rendered models and diagrams, but also rely heavily on highly informal renderings on the chalkboard and largely one-handed gestures used to make and reinforce the processes implied in these and other representations. These performances and representations extend to more emphatic gestural enactments made using the lecturer's own body as a representational device. They also include the prosody of the instructor's own narration, emphasizing as it does the motion and action that is indicated through his gestures and the content of his speech itself.

In the face of all similarity that we may observe in the case of each sense-giving repetitionwhether it is Harvey's varying descriptions and metaphors or the teacher's manifold and layered enactments - an element of difference is unavoidably present. These repetitions consequently do not have the character of redundant, mechanical iterations or duplications, but of a kind of rhythmical, habitual re-occurrence. This mixture of sameness and difference produces a pattern or structure that is familiar to us from melody and music, from the rhythms and regularity of everyday life and daily practices. It allows for an awareness of and familiarity with the action of the heart and the processes of the circulatory system to be communicated in the lecture (and also in Harvey's descriptions) not only in the form of overt information and transmitted knowledge, but also in the form of a kind of 'passive receptivity' or 'passive synthesis': A participation in a rhythm, cadence, or recurrent habitude. It is certainly no accident that this is in an overt sense allied from pulse and beat of the heart itself, a rhythm and regularity that is itself constantly but subtly varied, and that insistent and unceasing in its accompaniment of our sensual lives.

In this paper, a case is made for the historical reconstruction of the original sense-constituting acts that gave rise to what is now recognized as canonical science (as mathematics, social science, literature). Such reconstructions are important because the conditions of the original sense constitutions also function in the reproduction of the knowledges to the present day, that is, 
in the acts by means of which students come to know the fundamentals of the knowledges contained in the curriculum guidelines of the relevant jurisdiction. Because lectures are an important part of the secondary school and university courses, it is crucial to understand precisely what the conditions are for knowledges to emerge from the pre- and non-scientific knowledges. In this article, we exemplify such a reconstruction in the context of anatomy and physiology by comparing texts and lecture notes produced during and as part of the scientific revolution and present-day biology lectures on the topic. We show that the lecture appeals to observations of the kind that the founder of the science (Harvey) would have made during his dissections and vivisections. The realia of the two situations, however, were different as the founder drew on natural objects (live animals, corpses of deceased humans) whereas the biology teacher, though he also referred to and gestured over and above his body, generally worked with representations along a spectrum where inscriptions have more or less surface similarity with the original phenomenon. In our effort, therefore, we have enacted what the introductory quotation has urgently called for: the reconstruction of the relationship between scientific and pedagogical knowledge.

\section{Acknowledgements}

Grants from the Social Sciences and Humanities Research Council of Canada supported the collection of the data. We are grateful to our research assistants at the time, Lilian PozzerArdenghi and Diego Ardenghi, for their help in establishing the database.

\section{References}

Bachelard, G. (1966) Le rationalisme appliqué (Paris, France: Presses Universitaires de France). Barke, H.-D., Hazari, A. and Yitbarke, S. (2009) Misconceptions in Chemistry: Addressing Perceptions in Chemical Education (Dordrecht: Springer). 
Bjelic, D. (1992) The praxiological validity of natural scientific practices as criterion for identifying their unique social-object character: The case of the 'authentication' of Goethe's morphological theorem. Qualitative Sociology, 3: 221-245.

Bjelic, D. (1996) Lebenswelt structures of Galilean physics: the case of Galileo's pendulum. Human Studies, 19: 409-432.

Bjelic, D. and Lynch, M. 1992. The work of [scientific] demonstration, respecifying Newton's and Goethe's theories of prismatic color. In Text in Context, Edited by: Watson, G. and Seiler, R. M. 52-78. London: Sage.

Brüstle, C., Ghattas, N., Risi and Schouten, S. (2005) Zur Einleitung: Rhythmus im Prozess. In Aus dem Takt: Rhythmus in Kunst, Kultur und Natur, Edited by: Brüstle, C., Ghattas, N., Risi and Schouten, S. 9-27 (Bielefeld: transcript).

Deleuze, G. (1968) Différence et répétition (Paris: Presses Universitaires de France).

Derrida, J. (1962) Introduction à 'L'Origine de la géométrie' de Husserl (Paris, France: Presses Universitaires de France).

Derrida, J. (1990). Le problème de la genèse dans la philosophie de Husserl (Paris, France: Presses Universitaires de France).

Foucault, M. (1966) Les mots et les choses: Une archéologie des sciences humaines (Paris, France: Gallimard).

Garfinkel, H. (1996) Ethnomethodology's program. Social Psychology Quarterly, 59: 5-21.

Garfinkel, H. (2002) Ethnomethodology's Program: Working out Durkheim's Aphorism (Lanham, MD: Rowman \& Littlefield).

Glimcher, P. W. (2005) The heart of medicine. PLoS Biology 3 (12): e425. doi:10.1371/journal.pbio.0030425

Gross, P. R. and Levitt, N. (1994) Higher Superstition: The Academic Left and Its Quarrels With Science (Baltimore: Johns Hopkins University Press).

Harvey, W. [Harveius, G.] (1628). Exercitatio anatomica de motu cordis et sanguinis in animalibus. Frankfurt, Germany: W. Fitzer. 
Harvey, W. (1889) On the Motion of the Heart and Blood in Animals (London, UK: George Bell).

Husserl, E. (1928) Vorlesungen zur Phänomenologie des inneren Zeitbewußtseins. Jahrbuch für Philosophie und phänomenologische Forschung, 9: 367-496.

Husserl, E. (1939) Die Frage nach dem Ursprung der Geometrie als intentional-historisches Problem. Revue Internationale de Philosophie, 1: 203-225.

Husserl, E. (2008) Husserliana. Gesammelte Werke Band XXXIX. Die Lebenswelt. Auslegungen der vorgegebenen Welt und ihrer Konstitution. Texte aus dem Nachlass (1916-1937) (Dordrecht: Springer).

Kuhn, T. S. (1970) The Structure of Scientific Revolutions (Chicago: University of Chicago Press).

Labinger, J. A. and Collins, H. (eds.) (2001) The One Culture? A Conversation About Science, (Chicago: University of Chicago Press).

Latour, B. (1993) La clef de Berlin et autres leçons d'un amateur de sciences (Paris: Éditions la Découverte).

Livingston, E. (1986) Ethnomethodological Foundation of Mathematics (London: Routledge).

Maxwell, J. C. (1865) A dynamical theory of the electromagnetic field. Philosophical Transactions of the Royal Society of London, 155: 459-512.

McNeill, D. (2005) Gesture and Thought (Chicago: Chicago University Press).

Medical Discoveries. (2012) Harvey, William. Accessed September 20, 2012 at http://www.discoveriesinmedicine.com/General-Information-and-Biographies/HarveyWilliam.html

Nature. (1928) News and views. Nature, 121: 507-512.

Pozzer-Ardenghi, L. and Roth, W.-M. (2007) On performing concepts during science lectures. Science Education, 91: 96-114.

Pozzer-Ardenghi, L. and Roth, W.-M. (in press) A cultural-historical perspective on the development of concepts and ideas in science lectures. Cultural Studies of Science 


\section{Education.}

Pozzer-Ardenghi, L. and Roth, W.-M. (2009) How do we know he is not talking about himself? Demonstrations in science classrooms. Journal of Pragmatics, 41: 684-698.

Roth, W.-M. (2008) The nature of scientific conceptions: A discursive psychological perspective. Educational Research Review, 3: 30-50.

Roth, W.-M. (2009) Radical uncertainty in scientific discovery work. Science, Technology \& Human Values, 34: 313-336.

Roth, W.-M. (2012) Mathematical learning, the unseen and the unforeseen. For the Learning of Mathematics, 32 (3).

Roth, W.-M. and Bowen, G. M. (1999) Complexities of graphical representations during lectures: A phenomenological approach. Learning and Instruction, 9: 235-255.

Roth, W.-M. and Lawless, D. (2002) When up is down and down is up: Body orientation, proximity and gestures as resources for listeners. Language in Society, 31: 1-28.

Roth, W.-M. and McGinn, M. K. (1998) Inscriptions: a social practice approach to 'representations'. Review of Educational Research, 68: 35-59.

Roth, W.-M., McRobbie, C., Lucas, K. B. and Boutonné, S. (1997) Why do students fail to learn from demonstrations? A social practice perspective on learning in physics. Journal of Research in Science Teaching, 34: 509-533.

Tröhler, D. (2008) The knowledge of science and the knowledge of the classroom: Using the Heidelberg Catechism (1563) to examine overlooked connections. In Scholarly Knowledge, Edited by Campi, E., de Angelis, E. S., Goeing, A.-S. and Grafton, A. T. (Geneva: Droz), $75-85$.

van Eijck, M. and Roth, W.-M. (2011) Cultural diversity in science education through novelization: Against the epicization of science and cultural centralization. Journal of Research in Science Teaching, 48: 824-847. 


\section{Captions}

Figure 1 The text from On the Motion of the Heart and Blood in Animals (Harvey 1889: 68), read as instruction, and figures (Harvey 1889: 69) enable present-day readers to make precisely those observations that led to the original constitution of anatomy as a modern science and the modern view of the circulatory system.

Figure 2 Visually enhanced examples of different naturalistic drawings and abstract diagrams featured throughout the 7 lectures on the heart and circulatory system.

Figure 3 Gesture that goes with the articulation of 'Contracting'

Figure 4 Gesture that goes with the articulation 'Receiving'

Figure 5 Gesture that goes with the statement 'The heart takes it from the left ventricle up and out'

Figure 6 Associated with a hand gesture and pointed index, the teacher prosodically-mainly pitch, but also speech intensity_makes 'up' and 'out' stand out.

Figure 7 Two- and one-handed gestures that accompany the statement 'up and out' 


\section{Bios}

Wolff-Michael Roth is Lansdowne Professor of applied cognitive science at the University of Victoria, MacLaurin Building, University of Victoria, Victoria, BC, V8W 3N4, Canada; email: wolffmichael.roth@gmail.com. His cross-disciplinary research concerns knowing and learning in science and mathematics across the lifespan. He is author of Geometry as Objective Science in Elementary School Classrooms: Mathematics in the Flesh (New York: Routledge, 2011).

Norm Friesen is Canada Research Chair in E-Learning Practices at Thompson Rivers University, 900 McGill Rd. Kamloops, British Columbia Canada V2C 5N3; email: nfriesen@tru.ca. He uses phenomenology and ethnomethodology to investigate experiences of engagement with e-learning technologies. He is author of Re-Thinking E-Learning Research: Foundations, Methods and Practices (New York: Peter Lang, 2009) 
Let an arm be tied up above the elbow as if for phlebotomy ( $A, A$, fig. 1 ). At intervals in the course of the veins, especially in labouring people and those whose veins are large, certain knots or elevations (B, C, D, E, F) will be perceived, and this not only at the places where a branch is received $(E, F)$, but also where none enters $(C, D)$ : these knots or risings are all formed by valves, which thus show themselves externally. And now if you press the blood from the space above one of the valves, from $\mathrm{H}$ to $\mathrm{O}$, (fig. 2 ,) and keep the point of a finger upon the vein inferiorly, you will see no influx of blood from above; the portion of the vein between the point of the finger and the valve $O$ will be obliterated; yet will the vessel continue sufficiently distended above the valve $(O, G)$.

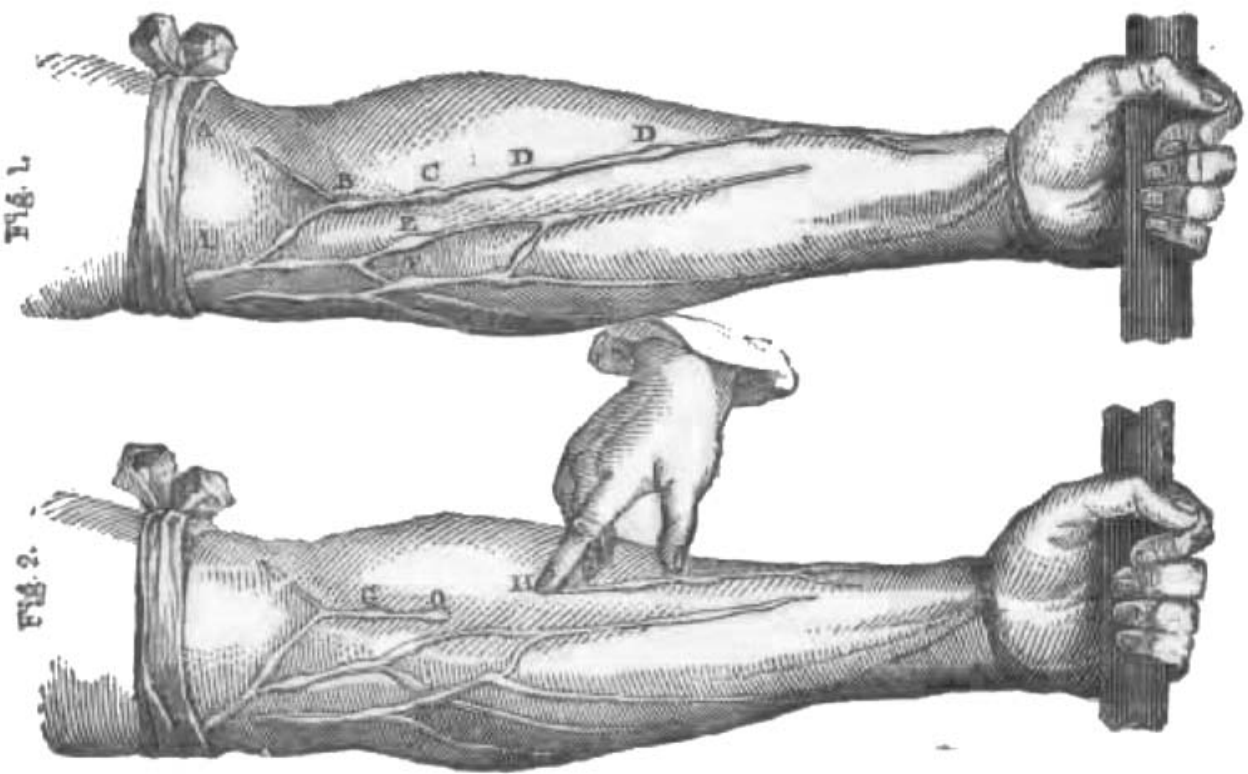





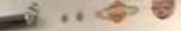

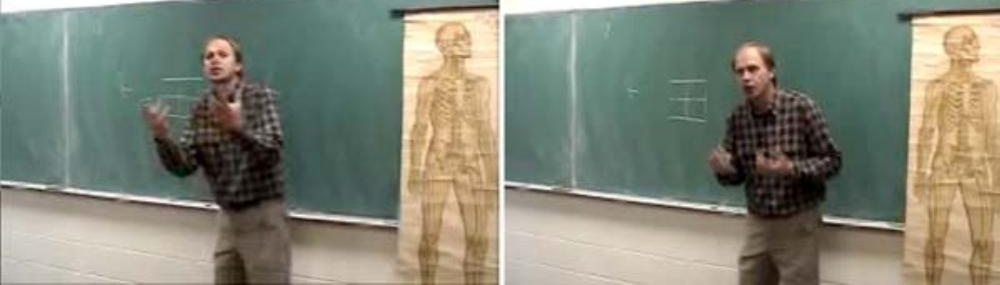


7

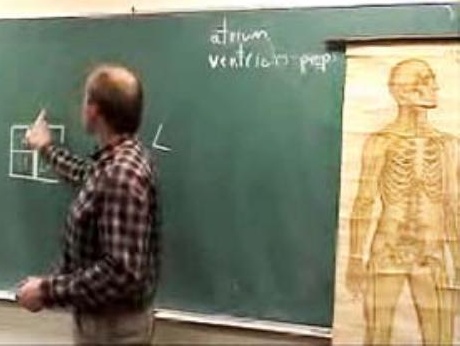




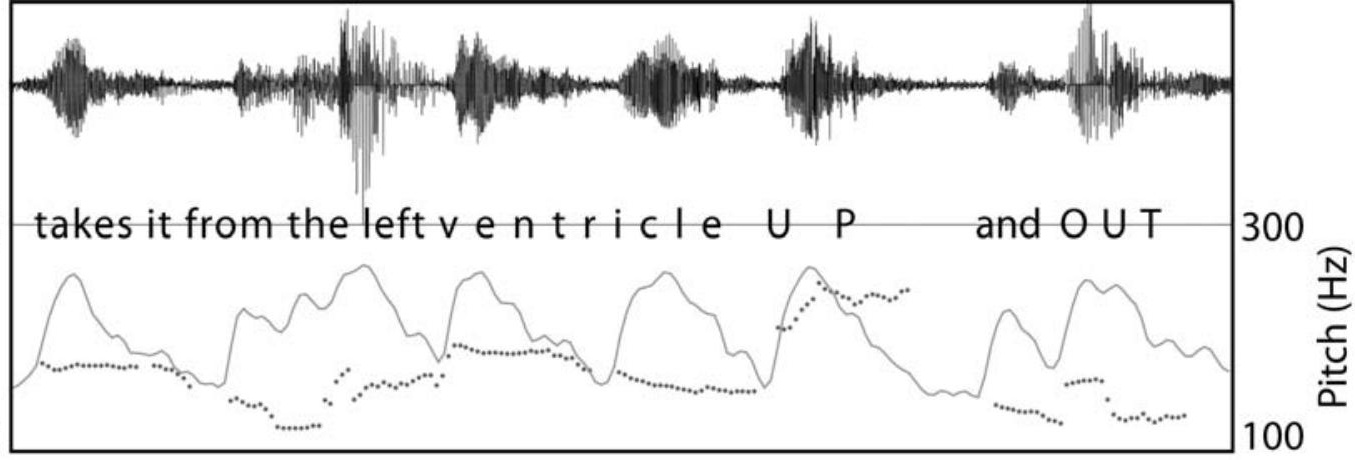




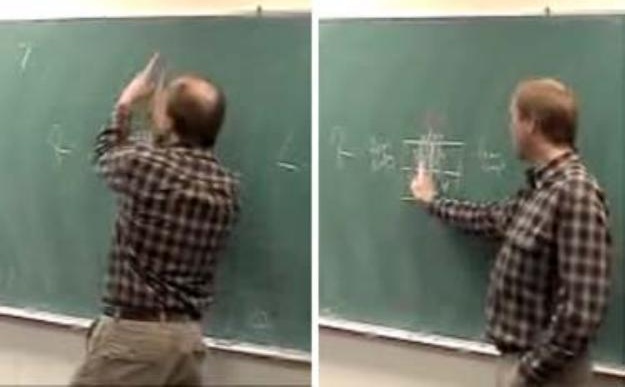

